UDK 582.711.712:574.56.085.2

(C) 2016

O. Oliynyk

A. Kliuvadenko, candidate of agricultural sciences

A. Likhanov, candidate of biological sciences

National University of Bioresources and Natural Resources of Ukraine

M. Melnichuk, academician of the NAAS, doctor of biological

sciences National Academy of Agrarian Sciences of Ukraine

\title{
INFLUENCE OF PHENOLIC MATTERS UPON EFFICIENCY OF USE OF CULTIVARS ROSA DAMASCENA MILL. AS CROP IN VITRO
}

The purpose. To study links between strain-specificity of polyphenolic bonds and recovery processes of explants of rose-tree in conditions in vitro. Methods. Culture of tissues and organs of plants in vitro, thin-layer chromatography, spectophotometry. Results. It is fixed that the greatest content of phenolic bonds is characteristic for cultivars of rose-tree Lada and Raduga, and the least one - for cultivar Lan. It is determined that the heightened content of phenolic bonds and their accumulation in tissues and nutrient medium negatively influences sterilization and recovery processes of primary explants in vitro. Conclusions. Quality content and amount of simple phenols and condensed tannins in leaves of rose-tree of essential oilbearing cultivars Lada, Lan, Raduga is the marker of potential ability of scions of cultivars of essential oilbearing rose-tree to neogenesis. In conditions of presence of phenolic bonds in leaves of primary explants in density below $60 \mathrm{mg} / \mathrm{g}$ of crude mass efficiency of use of plants as crop in vitro is increased.

Key words: essential oilbearing rose-tree, explants, nutrient medium, phenolic bonds, crop in vitro.

Conclusions. The qualitative composition and quantity of simple phenols and condensed tannins in the leaves of rose essential oil varieties Lada, Lan', Raduga is a marker for potential ability shoots to regeneration. The effectiveness of the introduction of plants into culture in vitro is increased if the content of phenolic compounds in leaves primary explants in a concentration below $60 \mathrm{mg} / \mathrm{g}$ wet weight.

Biologically active compounds of phenolic nature are synthesized in the leaves of of the Rosaceae family: aglucones of flavonoids - 
campsferol and quercetin and their glycosides, pyrokatechin, pyrogalol, eugenol, procianidine. The main of them is epicatechin [2]. In young stems were detected galactic and ferulic acids, epicatechin, galatanin and prodicanine dimers. In tissues of healthy stems is accumulating flavonoids-3-ol (-) - epicatechins, monomers, diamers and procyanide polymers. In petals of roses, additionally synthesized elagma, gentizin, coffee, protokatechova, $p$ - hydrobenzene, p-kumarova, sirinova, vanillin and salicylic acid. Which are usually not found in stems, or their number is negligible $[7,8]$. Phenolic compounds, such as catechins and tannins, can protect injured and adjacent tissues from free radicals, which are formed as a result of active cell breathing [1]. Under the influence of high doses of ultraviolet radiation roses cells are accumulate approximately 15 times more flavonoids and are able to form twice the amount of DNA [8]. Oxidation of polyphenols leads to the formation of compounds that inhibit growth processes and complicate the regeneration of tissues [10]. In the culture of roses, the synthesis of common phenols and leukoanthocyanins is positively influenced by an increase in the concentration of exogenous glucose. Synthesis of leucoanthocyanins decreases with increasing content in the nutrient medium of nitrates, but the synthesis of common phenols does not affect this factor $[2,4]$. The interest of the dynamics of the synthesis and localization of polyphenols in tissues Rosa L. due to their influence on regenerative processes in culture in vitro $[9,10]$. The purpose of our work was to study the relationships between the sortspecific composition of polyphenolic compounds and the regenerative processes of roses explants in vitro.

\section{Materials and methods of research}

For researches were used roots of varieties Lan', Lada, Raduga of Ukrainian breeding (authors L.G.Nazarenko and L.A. Grishchenko). Raduga is fast-growing variety. It has a compact bush, medium-sized spiked shoots and bright pink flowers. Lan' is a technological grade 
resistant to rust, has a low density and bright pink flowers. Lada variety is characterized by high butogenicity, has winter resistance, an average pruritus, resistant to rust, flowers are pale pink [5]. Shoots $20-30 \mathrm{~cm}$ in length with axillary buds were isolated from 2-year-old donor plants.

Cuttings were placed in a vessel with water and kept under controlled conditions( $T$

$=24 \pm 2^{\circ} \mathrm{C}$, relative humidity $60-70 \%$ ) to reduce the infection of the plants pathogens of fungal and bacterial nature. For effective neutralization of exogenous microflora, the sterilization of explants was carried out in two stages: in non-sterile conditions and in conditions of laminar boxing. In non-sterile conditions, the explants were washed in a soapy solution for 10-15 minutes on a shaker, then they were washed in running water for 10-15 minutes and rinsed in distilled water. Sterilization of the explants was carried out with solutions: $70 \%$ $\mathrm{C} 2 \mathrm{H} 5 \mathrm{OH}$ (1-2 min.), $0.1 \% \mathrm{HgCl} 2$ (5-10 min.). The sterilized explants were washed in sterile distilled water three times for $10 \mathrm{~min}$. In sterile conditions, they were cut into fragments in length of $1.0-1.5 \mathrm{~cm}$ with one bud [3]. Operations were performed in laminar boxes YLGH-19 (Germany). The total content of phenolic compounds in plant material was determined by spectrophotometric method by using reagent Folin Chokolteu. The calibration graph was constructed on halic acid. The amount of flavonoids was determined in methanol extracts $(1: 10)$ at $\lambda=$ $419 \mathrm{~nm}$ on a scintigraphic spectrophotometer Optizen Pop, successively adding $300 \mu \mathrm{l}$ of $0.1 \mathrm{M}$ solution of $\mathrm{AICl} 3$ and $500 \mu \mathrm{l}$ of $1 \mathrm{M}$ $\mathrm{CH} 3 \mathrm{CONa}$ to $500 \mu \mathrm{l}$ of extract. As a standard was used quercetin (Merk, Germany) [6] .

\section{Research results}

According to the research results, the largest total content of alcoholsoluble phenolic compounds was determined in the leaves of the rose varieties Lada and Raduga, the smallest in the Lan' variety (Tab. 1). The latter can be characterized as a low-grade phenolic compound. He 
showed the highest regenerative ability, according to the conditions we have selected for sterilization and cultivation of primary explants in vitro.

Table 1

The content and ratio of phenolic compounds in the leaves of rose essential oil

\begin{tabular}{|c|c|c|c|}
\hline \multirow{2}{*}{ Variet } & \multicolumn{2}{|c|}{ Phenols, $\mathrm{mg} / \mathrm{g}$} & Ratio \\
\cline { 2 - 4 } & fenols & flavonoids & $\begin{array}{c}\text { fenols/flavonoid } \\
\text { s }\end{array}$ \\
\hline Lada & $118,9 \pm 4,8$ & $11,9 \pm 0,5$ & $10,0 \pm 0,4$ \\
\hline $\begin{array}{c}\text { Rainbo } \\
\text { w }\end{array}$ & $109,1 \pm 4,4$ & $11,7 \pm 0,5$ & $9,3 \pm 0,4$ \\
\hline Lan & $63,0 \pm 2,5$ & $10,8 \pm 0,4$ & $5,8 \pm 0,2$ \\
\hline
\end{tabular}

The difference in the quantitative indices of the content of phenols and flavonoids in the varieties of Lada and Raduga was unreliable. Flavonoids in a plant organism perform various physiological functions. Therefore, the ratio of the total number of phenols to flavonoids is an informative indicator of the direction of the processes of secondary metabolism. The advantage of the mass fraction of substances of phenylpropanoid synthesis over the flavonoid complex can be characterized by an adaptation strategy of plants. It was found that the lowest indicator was in the Lan' variety - 5.8, for Lada and Raduga 10.0 and 9.3 , respectively.

In the introduction of primary explants of roses into in vitro culture in the tissues of the primary cortex, secondary phloem and parenchyma of the heart beams is observed an intense synthesis of phenolic compounds, such as tannins and flavonoids. Secondary metabolites in the baspettal direction are actively moving along the sieve tubes and parenchyma cells. Part of the phenols diffuses into the nutrient medium and oxidizes under sufficient amounts of oxygen. The rest (proanthocyanidins, flavonoids) forms complex polymers that can specifically bind to the proteins of cell membranes and influence their selectivity and transmembrane transfer. It essentially changes the 
functional state of living cells. The nature and direction of biochemical processes depends on the qualitative composition of polyphenols. The study of sortspecific differences in the qualitative composition of phenolic compounds by thin-layer chromatography showed: In the leaves of plants of the Lada variety, in comparison with other, there is a smaller number of catechins, but the variety differences in their qualitative composition are not found. It was also found there is feedback between the regenerative ability of explants and starting pool of phenolic compounds. It was determined that at the stage of introduction into culture in vitro, the most difficult adaptations were Lada and Rainbow varieties (Fig. 1, Б-В; Г-Д), the highest regenerative capacity, according to the sterilization conditions we selected, in the Lan variety (Fig. 1, A, E).

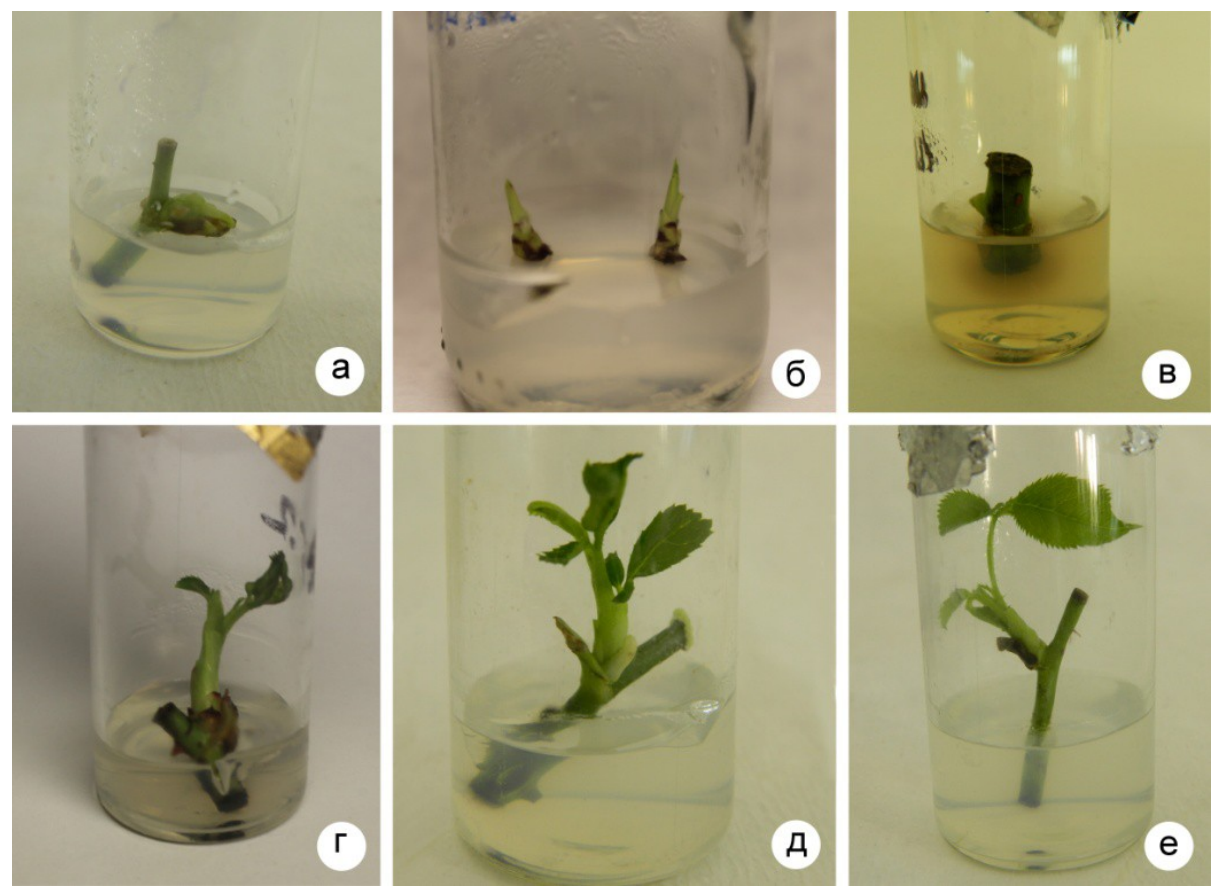

Fig.1 Sterile explants at the stage of introduction into culture in vitro: A - Lan variety, B - Lada variety, B - Raduga variety (7 days of cultivation); activation of the axillary kidneys: $\Gamma$ - grade Lada; Д Raduga variety; E - Lan' (21 days of cultivation)

Plants of the first of them contained in the leaves the substance (Fig. 2, A), which in the variety Lan' was detected only in the nutrient medium under conditions of cultivation of plants in vitro. 


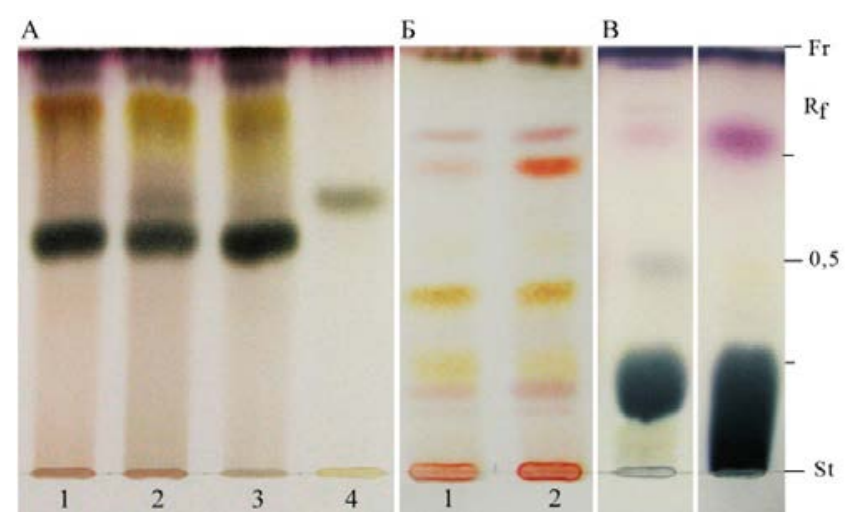

Fig. 2. Chromatogram of extracts of secondary metabolites of rosemary essential oils contained in leaves $(A)$, shoots $(5)$ and isolated in the medium $(B)$ by primary explants during the introduction into culture in vitro: 1 - varietal Lan'; 2 - varietal Lada ; 3 - Raduga variety; 4 - diffuser of the Lada variety: A - chloroform - acetic acid - methanol water: v / v / v / v - 60/32/12/8 (treatment with anisive aldehyde); B chloroform - ethyl acetate - methanol - formic acid: $\mathrm{v} / \mathrm{v} / \mathrm{v} / \mathrm{v}$ $50 / 40 / 10 / 10$ (treatment with $1 \%$ vanillin and $5 \%$ sulfuric acid); $V$ toluene - ethyl acetate - acetic acid - formic acid - water: $v / \mathrm{v} / \mathrm{v} / \mathrm{v}$ 1/20/2/2/2 (treatment with anisive aldehyde)

Individual compounds isolated and purified from the nutrient medium showed characteristic electronic condensed tannin spectra with absorption maxima in the range $240-280 \mathrm{~nm}$ (Fig. 3).
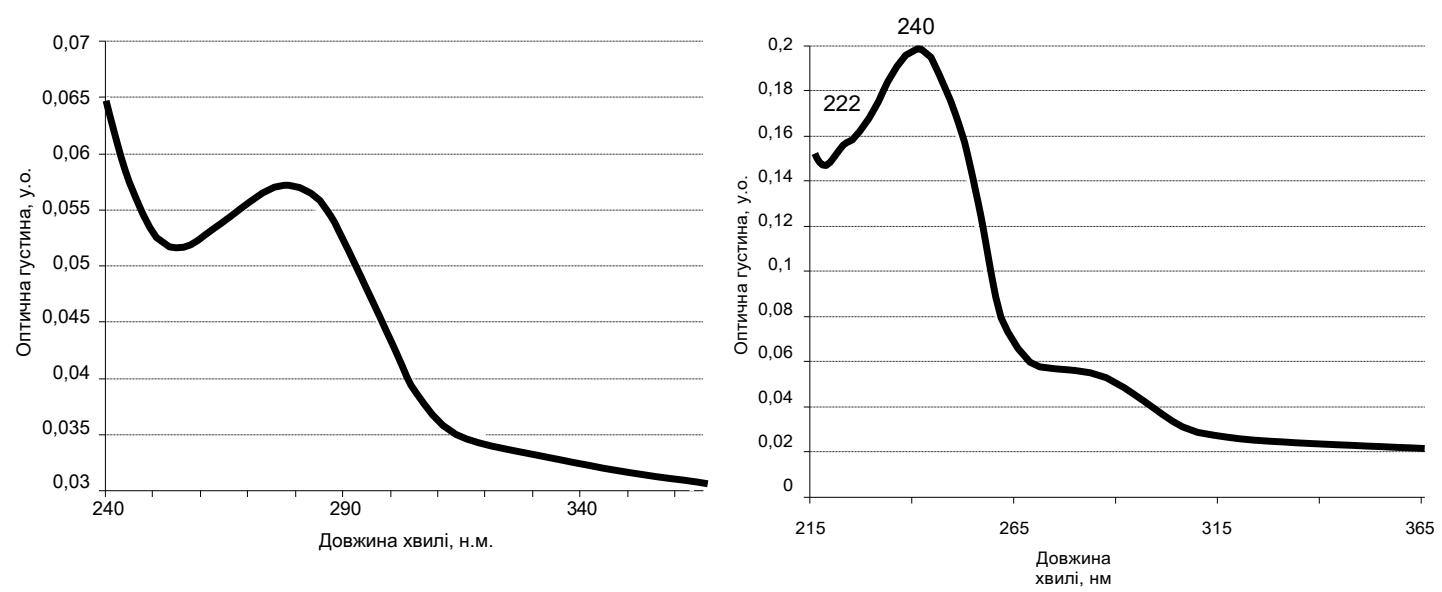
Fig. 3. Electronic absorption spectra of individual substances diffusing into the nutrient medium from the shoots of roses essential oil of the Lan' variety: a substance with $\mathrm{Rf} \sim 0.18$ (black spot on chromatogram), $\lambda \max =280 \mathrm{~nm} ; \mathrm{b}-\mathrm{Rf} \sim$ 0.80 (purple spot), $\lambda \max =240 \mathrm{~nm}$

Assessment of the effects of individual compounds isolated from the nutritional medium, found their ability to inhibit the germination of radish seeds. This confirmed their possible role in suppressing the regeneration processes of the shoots.

\section{Conclusion:}

1. The qualitative composition and quantity of simple phenols and condensed tannins in the leaves of rose essential oil varieties Lada, Lan', Raduga is a marker of the potential of Rosa damascena Mill. before regeneration.

Efficiency of introduction of plants into culture in vitro significantly increases with the content of phenolic compounds in the leaves of primary explants at a concentration below $60 \mathrm{mg} / \mathrm{g}$ of raw weight.

2. The intensity of accumulation in the roses essential oil of phenolic compounds and the rate of their diffusion in the solid nutrient medium characterize the efficiencyof the conditions of sterilization of primary explants and the optimality of the composition of the nutrient medium.

\section{Bibliography:}

1. Andreeva V. A. (1988) Ferment peroksydaza: uchastye v zashchytnom mekhanyzme rastenyi [The enzyme peroxidase: participation in the defense mechanism of plants]. M.: Science, $128 \mathrm{p}$. 2. Zaprometov, M. N.(1993) Fenolnye soedynenyia. Rasprostranenye, metabolyzm y funktsyia $v$ rastenyiakh [Phenolic compounds. Distribution, metabolism and function in plants]. M.: Science, 272p.

3. Kalynyn, F. L., Kushnyr, H. P., Sarnatskaia, V. V. (1992) Tekhnolohyia mykroklonalnoho razmnozhenyia rastenyi [Technology 
microclonal plant propagation]. K.: Scientific thought, 232p.

4. Makarevych, A. M., Shutova, A. H., Spyrydovych, E. V., Reshetnykov E. V.(2010) Funktsyy y svoistva antotsyanov rastytelnoho Syria [The functions and properties of anthocyanins vegetable raw materials]. Trudy BHU №2, pp.1-11

5. Pylunskaia, O. A. (1999) Vvedenye v kulturu in vitro rozy efyromaslychnoi [Introduction to culture in vitro aromatic rose]. Proceedings of the Crimean State Agricultural University, pp.88-97 6. Pochynok, Kh. N.(1976) Metody byokhymycheskoho analyza rastenyi [Methods of biochemical analysis of plants]. K.: Scientific thought, 336p.

7. Charles S. B., Imin N., Djordjevic M. A. Flavonoids: new roles for old molecules//Journal of Integrative Plant Biology. - 2010. - V. 52 (1). - Pp. 98-111.

8. Charles S.B., Muday G.K. The transparent testa mutation prevents flavonoid synthesis and alters auxin transport and the response of arabidopsis roots to gravity and light//The Plant Cell. - 2004. - V. 16 (5) . - pp. 1191-1205.

9. Plant pigments and their manipulation. - Ed. by K.M.

Davies//Annual plant reviews. - 2004. - V. 14. - 352 p.

10. Salekjalali M. Phloroglucinol, BAP and NAA Enhance Axillary Shoot Proliferation and other Growth Indicators in vitro Culture of Damask Rose (Rosa damascena Mill.)//Advances in Environmental Biology, 6(7).-2012.-P.1944-1949. 